\title{
VISUAL AND REFRACTIVE OUTCOMES WITH A NEW TOPOGRAPHY-INTEGRATED WAVEFRONT-GUIDED LASIK PROCEDURE
}

\section{Antonio Uceda-Montañés, Michael Rogers \& David P Piñero}

To cite this article: Antonio Uceda-Montañés , Michael Rogers \& David P Piñero (2020): VISUAL AND REFRACTIVE OUTCOMES WITH A NEW TOPOGRAPHY-INTEGRATED WAVEFRONTGUIDED LASIK PROCEDURE, Current Eye Research, DOI: 10.1080/02713683.2020.1822418

To link to this article: https://doi.org/10.1080/02713683.2020.1822418

Accepted author version posted online: 09 Sep 2020.

Submit your article to this journal $\llbracket$

View related articles $\asymp$

View Crossmark data [ᄌ 
PUBLISHER: TAYLOR \& FRANCIS

JOURNAL: CURRENT EYE RESEARCH

DOI: $10.1080 / 02713683.2020 .1822418$

VISUAL AND REFRACTIVE OUTCOMES WITH A NEW

TOPOGRAPHY-INTEGRATED WAVEFRONT-GUIDED

LASIK PROCEDURE

Running head: Results of a new wavefront-guided LASIK procedure

Authors:

Antonio Uceda-Montañés, MD, Cert. LRS RCOphth ${ }^{1,2}$

Michael Rogers, $\mathrm{OD}^{1}$

David P Piñero, $\mathrm{PhD}^{3}$

${ }^{1}$ Optilase Eye Clinics, Dublin, Ireland

${ }^{2}$ Medical Monitor, Johnson \& Johnson Vision, EMEA

${ }^{3}$ Department of Optics, Pharmacology and Anatomy, University of Alicante, Alicante, Spain

\section{Correspondence:}

David P Piñero, PhD

Corresponding Address:

Department of Optics, Pharmacology and Anatomy. University of Alicante

Crta San Vicente del Raspeig s/n 
03690 San Vicente del Raspeig, Alicante

Spain

Mail: david.pinyero@ua.es

Tel. +34965903400

Fax. +34965903464

\section{Disclosure}

Antonio Uceda-Montañés received an unrestricted educational grant from Johnson \& Johnson Vision

The author David P Piñero has been supported by the Ministry of Economy, Industry and

Competitiveness of Spain within the program Ramón y Cajal, RYC-2016-20471

The authors have no proprietary or commercial interest in the medical devices that are involved in this manuscript. 


\begin{abstract}
Purpose: To evaluate the clinical outcomes of laser in situ keratomileusis (LASIK) using a new approach for the calculation of the ablation profile based on wavefront vertexing from pupil plane to corneal.

Methods: One hundred eyes of 50 patients (age, 21-41 years) with low and moderate myopia were enrolled in this prospective case series. All of them underwent topography-integrated wavefront-guided (TI-WFG) LASIK using the STAR S4IR excimer laser platform (Johnson \& Johnson Vision). Visual, refractive, ocular aberrometric, ocular scattering index (OSI) and patient satisfaction outcomes were evaluated after a 90-day follow-up period. Astigmatic changes were evaluated by vector analysis.
\end{abstract}

Results: A significant reduction in sphere and cylinder $(\mathrm{p}<0.001)$ was observed, with a significant improvement in uncorrected (UDVA) and corrected distance visual acuity (CDVA) $(\mathrm{p}<0.001)$. Postoperative spherical equivalent was within \pm 0.50 and $\pm 1.00 \mathrm{D}$ in $91.1 \%(82 / 90)$ and $98.9 \%(89 / 90)$ of eyes, respectively. UDVA was $20 / 20$ or better in $98.9 \%(89 / 90)$ of eyes. A total of $50.0 \%(45 / 90)$ of eyes gained 1 line of CDVA. Mean postoperative astigmatic correction index and angle of error were $1.01 \pm 0.56$ and $0.17 \pm 0.18^{\circ}$. Postoperative high order aberrometric coefficients were below $0.50 \mu \mathrm{m}$ in $92.2 \%(83 / 90)$ of eyes. Mean postoperative OSI was $0.71 \pm 0.44$. All patients referred to be satisfied with the final outcomes and would recommend the procedure to their friends and relatives. 
Conclusions: TI-WFG LASIK is a new approach for myopia and myopic astigmatism correction, with preservation of the ocular optical quality and high level of patient satisfaction associated

Keywords: wavefront-guided LASIK, high order aberrations, topography-guided LASIK, myopia, astigmatism 


\section{INTRODUCTION}

Wavefront-guided (WFG) laser in situ keratomileusis (LASIK) has demonstrated to be a safe and effective procedure for the correction of refractive errors for many years. ${ }^{1-3}$ This type of procedures has been shown to promote not only a visual improvement but also significant improvements in subjective functional vision and vision-related quality of life one year after surgery. ${ }^{4}$ In recent years, WFG LASIK has been enhanced due to several factors, most notably improvements in wavefront aberrometry and optimizations in femtosecond and excimer laser technologies. ${ }^{5}$ The introduction of high resolution wavefront aberrometers has led to an accurate and consistent characterization of the aberrometric pattern of any eye, ${ }^{6,7}$ including highly aberrated eyes, creating more advanced laser ablation profiles. ${ }^{8}$ In a recent randomized fellow eye controlled clinical trial, ${ }^{8}$ wavefront-optimized and high-resolution WFG LASIK have shown to provide excellent visual outcomes, nonetheless WFG treatments based on the high-resolution aberrometer offered superior results in some aspects, including refractive predictability and postoperative level of high order aberrations (HOAs).

Topography-integrated wavefront-guided (TI-WFG) LASIK is a new approach for calculating the ablation profile based on the combination of topography and ocular wavefront aberrations obtained with a previously validated high-resolution topographeraberrometer. ${ }^{6,7}$ Since no clinical reports of this technique are available in the literature, the aim of the current study was to investigate the 3 month post-operative visual, refractive and optical quality outcomes in low to moderate myopic eyes with different levels of astigmatism. 


\section{Patients and methods}

\section{Patients}

This prospective consecutive case series enrolled 100 eyes of 50 patients ranging in age from 21 to 41 years old screened for laser refractive surgery at Optilase Eye Clinic in Ireland. All cases presented low to moderate myopia with different levels of astigmatism and HOAs. All cases underwent TI-WFG LASIK using the STAR S4IR excimer laser combined with the iDesign system for treatment calculation (Johnson \& Johnson Vision, Jacksonville, FL). Inclusion criteria for the study included myopic spherical refraction up to $-6 \mathrm{D}$ of sphere and manifest astigmatism below $-2 \mathrm{D}$ seeking for a laser refractive surgical solution to obtain spectacle independence. Exclusion criteria included patients with refractive errors out of the range defined in the inclusion criteria, active ocular pathology or media opacities, dry eye, unstable refraction for the last 12 months, residual corneal bed thickness below $300 \mu \mathrm{m}$, previous intraocular or corneal surgery, history of immunodeficiency or systemic connective tissue diseases, corneal alterations compatible with corneal ectatic disease, iris irregularities, and pregnancy or breastfeeding. The study received the approval of the Optilase Eye Medical Review Board. Patients were informed about the inclusion in the clinical study and gave informed consent to participate in it in accordance with the tenets of the Declaration of Helsinki.

\section{Examination protocol}

A complete preoperative ophthalmological examination was performed in all cases. Soft and rigid gas permeable contact lens wearers were asked to remove lenses at least one week and three weeks before the preoperative examination, respectively, in 
order to avoid the interference of any potential contact lens-related corneal warpage with our analysis. The preoperative exam included objective and manifest refraction, measurement of uncorrected (UDVA) and corrected distance visual acuity (CDVA), slit-lamp anterior segment examination, ultrasound pachymetry, corneal topography and ocular aberrometry measured with the iDesign 2.0 system (Johnson \& Johnson Vision, Jacksonville, FL), applanation tonometry, and funduscopy. In the aberrometric analysis, the magnitude of the root mean square (RMS) for high order aberrations (HOAs), and the Zernike terms corresponding to primary vertical and horizontal coma, and primary spherical aberration (SA) for a pupil aperture of $6 \mathrm{~mm}$ were calculated and recorded.

After surgery, a follow-up visit was performed the day after surgery to test UDVA and to assess the integrity of the corneal flap. The following clinical examinations were performed at 1 week, 1 month and 3 months postoperatively, including all of them UDVA and CDVA measurement, manifest refraction, biomicroscopic examination, corneal topographic analysis and ocular aberrometric analysis. In the last postoperative visit, an analysis of the ocular optical quality was also performed with a double-pass device that provides an estimation of light scattering [HD Analyzer, Optical Quality Analysis System (OQAS), Visiometrics SL]. Likewise, all patients were asked about their satisfaction with outcomes obtained after surgery using the following closed questions: Are you satisfied with the final outcomes?, Would you have the same surgical procedure again?, and Would you recommend this procedure to your friends and relatives?.

\section{Surgery}

All TI-WFG LASIK surgeries were performed by the same experienced surgeon (AUM). The iFS femtosecond laser technology Johnson \& Johnson Vision, 
Jacksonville, FL) was used to generate the corneal flaps, with an intended flap thickness of 110 microns $(\mu \mathrm{m})$ and a flap diameter between 8.5 and $9.3 \mathrm{~mm}$. Once the flap was generated, it was carefully lifted and the laser ablation carried out using the variable spot scanning excimer laser STAR S4IR (Johnson \& Johnson Vision, Jacksonville, FL). The ablation profile was calculated considering the data obtained with the iDesign 2.0 system. Treatments were programmed in all cases with a 6.0 to $6.7-\mathrm{mm}$ optical zone and a total ablation zone of $8.0 \mathrm{~mm}$, assuming a refractive target of emmetropia. Iris registration and eye tracking was used to ensure the centration of treatments during the ablation procedure. After ending the ablation, the stromal bed was irrigated with balanced saline solution and the flap repositioned. As standard postoperative treatment, a combination of dexamethasone and tobramycin was prescribed to be applied five times a day for one week, tapering the frequency during the two more following weeks. Also, patients were prescribed to use artificial tears at least every two hours the day after surgery and at least four times a day for one month.

The TI-WFG ablation profiles are the result of integrating in the same device corneal topography and ocular aberrometry (iDesign 2.0 system). Specifically, as corneal topographic data is available in the new iDesign 2.0 software, the actual local curvature data from corneal topography is used instead of extrapolated values based on keratometry. For the ablation profile generation, the corneal surface information is used for two different purposes: calculation of the cosine effect and wavefront propagation. It should be considered that when the corneal vertex is not at the ablation center, the eye is seen as tilted from the ablation center. Thus, the cosine effect has a slightly uneven level of compensation to capture the actual energy loss. With TI-WFG LASIK, two components transforming the wavefront information from the pupil plane to the spectacle plane are used. For the low-order aberrations, a standard vertex correction 
formula is used. For high-order aberrations, a keratometry-based spherocylindrical model was used to calculate each ray from pupil plane to spectacle plane with the previous version of iDesign, and thus not considering the local curvature variation of the human cornea (Table 1). With the new topo-integrated approach, each ray is propagated through the cornea based on the local curvature from the topographic map, being more accurate in capturing the local variation of the curvature of the cornea.

\section{Data analysis}

The commercially available software package SPSS was used to perform the statistical analyses with the data obtained in the clinical study (SPSS Version 20.0; IBM Corporation, Armonk, NY, USA). Normality of data samples was evaluated by means of the Kolmogorov-Smirnov test. When parametric analysis was possible, the Student $t$ test for paired data was used for the analysis of differences between preoperative and postoperative visits, whereas the Wilcoxon ranked sum test was used for such purpose when the data samples were not normally distributed. The conventional spherocylindrical refraction was transformed to Jackson crossed cylinder format to calculate $\mathrm{M}, \mathrm{J}_{0}$, and $\mathrm{J}_{45}$ from the refractive data ( $\mathrm{S}$ : sphere, $\mathrm{C}$ : cylinder, and $\alpha$ : cylinder axis) as the following:

$$
\mathrm{M}=\mathrm{S}+\mathrm{C} / 2 \quad \mathrm{~J}_{0}=(-\mathrm{C} / 2) \cos (2 \alpha) \quad \mathrm{J}_{45}=(-\mathrm{C} / 2) \sin (2 \alpha)
$$

These numbers are the coordinates of a point in a 3-dimensional dioptric space $\left(\mathrm{M}, \mathrm{J}_{0}, \mathrm{~J}_{45}\right) . \mathrm{M}$ is a spherical lens equal to the spherical equivalent (SE) of the given refractive error and $\mathrm{J}_{0}$ and $\mathrm{J}_{45}$ are the 2 Jackson crossed cylinders equivalent to the conventional cylinder. ${ }^{9}$ 
For all statistical tests, a p-value of less than 0.05 was considered as statistically significant.

Regarding the analysis of astigmatic changes occurring after surgery, the Alpins vector method was used. ${ }^{10,11}$ According to this methodology, the vectors targeted induced astigmatism (TIA), defined as the vector of intended change in cylinder for each treatment, surgically induced astigmatism (SIA), defined as the vector of the real change achieved, and the difference vector (DV), defined as the additional astigmatic change that would enable the initial surgery to achieve its intended target, were calculated. Likewise, other parameters characterizing the astigmatic change with surgery were calculated, including the magnitude of error (ME) (difference between the magnitude of SIA and TIA), correction index (CI) (SIA/TIA) and the angle of error (AE) (angle described by the vectors of SIA and TIA).

\section{RESULTS}

A total of 100 eyes from 50 patients ranging in age from 21 to 41 years were included in the study. All eyes had myopia or myopic astigmatism. A total of 28 $(56.0 \%)$ patients were female and $22(44.4 \%)$ were male. Mean ablation depth was $60.88 \mu \mathrm{m}$ (Standard deviation, SD: 18.03; median: 60.00; range: 30 to $103 \mu \mathrm{m}$ ) and mean flap diameter was $8.97 \mathrm{~mm}$ (Standard deviation, SD: 0.17; median: 9.00; range: 8.50 to $9.30 \mathrm{~mm})$.

\section{Visual and refractive outcomes}

Table 2 summarizes the preoperative and postoperative visual and refractive data obtained in our sample. A significant reduction was observed in sphere and cylinder at 1 
day after surgery $(\mathrm{p}<0.001)$, with a significant improvement associated in UDVA and CDVA $(p<0.001)$. A significant additional improvement in UDVA and CDVA was observed during the remaining follow-up $(\mathrm{p}<0.001)$. Likewise, significant changes were found in refractive parameters during the rest of follow-up $(p \leq 0.014)$, except for $\mathrm{J}_{0}$ $(\mathrm{p}=0.071)$ and $\mathrm{J}_{45}(\mathrm{p}=0.684)$. A total of $91.1 \%(82 / 90)$ and $98.9 \%(89 / 90)$ of eyes had a spherical equivalent within \pm 0.50 and $\pm 1.00 \mathrm{D}$ at 90 days after surgery, respectively (Figure 1). A total of $93.3 \%(84 / 90), 98.9 \%(89 / 90)$ and $100 \%(90 / 90)$ of eyes achieved UDVA of 20/16, 20/20 and 20/25 or better at 90 days after surgery, respectively (Figure 1). All eyes achieved a postoperative CDVA of 20/20 or better at the end of the followup. Regarding safety, no eye lost 2 lines or more of CDVA at 90 days after surgery and a total of $50.0 \%(45 / 90)$ of eyes gained 1 line (Figure 1).

\section{Vector analysis of astigmatic changes}

Table 3 displays the results of the vector analysis of astigmatic changes occurring during the follow-up after surgery. As shown, no significant changes in ME were detected during the follow-up, with a mean value of $-0.04 \mathrm{D}$ at 90 days postoperatively $(p=0.005)$. Likewise, no significant changes during the follow-up were detected in SIA and CI at 90 days after surgery, with mean values of $0.65 \mathrm{D}$ and 1.01, respectively. However, a small in magnitude but statistically significant increase in DV was observed $(\mathrm{p}=0.005)$. Concerning $\mathrm{AE}$, a significant reduction was observed during the follow-up, with a mean value at 90 days after surgery of $0.17^{\circ}$.

\section{Ocular optical quality outcomes}

Table 4 provides a summary of the preoperative and postoperative ocular aberrometric data obtained. A small in magnitude but statistically significant increase 
was observed in HOA RMS and spherical aberration Zernike term $(p<0.001)$, with only $7.8 \%(7 / 90)$ and $0 \%(0 / 90)$ of eyes showing postoperative values of more than $0.50 \mu \mathrm{m}$, respectively. Concerning coma, a small in magnitude but significant increase with surgery was found in the vertical $(p<0.001)$ and horizontal $(p=0.007)$ components of this type of aberration. Besides aberrations, the OQAS system was used to measure the ocular scattering index (OSI), obtaining a mean 90-day postoperative value of 0.71 (SD: 0.44; median: 0.60 ; range: 0.30 to 3.60 ).

\section{Patient satisfaction outcomes}

Concerning the questions about the satisfaction with the procedure, a total of $44(88.0 \%)$ patients answered them. All of them $(100.0 \%, 44 / 44)$ answered "Yes" when were asked about the satisfaction with the final outcomes, the possibility of having the same surgical procedure again if necessary, and the recommendation of the procedure to their friends and relatives.

\section{DISCUSSION}

Different studies have been conducted to evaluate the clinical outcomes after LASIK surgery using different types of ablation profiles. ${ }^{12}$ Wavefront-optimized (WFO) ablation profiles have been designed to minimize the induction of spherical-like aberrations and to generate more physiological postoperative corneal profiles. ${ }^{1,8}$ Likewise, ocular or total wavefront-guided ablations have been developed to optimize the ocular optics allowing a reduction of HOAs while minimizing the induction of new aberrations. ${ }^{1-3,8}$ This type of ablation profiles have been especially enhanced in recent years with the introduction of high resolution wavefront sensors. ${ }^{6,7}$ Besides these 
ablation profiles, topography-guided and corneal wavefront-guided ablations have been developed to reduce corneal irregularity and optimize corneal shape modifications with or without considering corneal wavefront analysis, respectively. ${ }^{13,14}$ This type of laser treatments are especially useful in highly aberrated corneas. ${ }^{13,14}$ Recently, a new concept of laser ablation profile has been developed that combines topography and ocular wavefront data, TI-WFG LASIK. This concept is basically based on wavefront vertexing from pupil plane to corneal plane as the laser ablation is performed on the corneal surface. Likewise, the corneal vertex location as well as the topography are characterized and considered for the laser cosine effect compensation of the laser ablation. Thus, the wavefront-guided laser profile is optimized considering the shape peculiarities of the surface on which it is going to be applied. The aim of the current prospective study was to analyze and report the outcomes obtained with this new concept of ablation profile. To our knowledge, this is the first series evaluating the outcomes of TI-WFG LASIK.

Good visual and refractive outcomes were found in the current study, being consistent with those reported by previous authors evaluating the results of WFG LASIK with different laser platforms. ${ }^{1-3,8,15-18}$ At 90 days after surgery, a total of $91.1 \%$ and $98.9 \%$ of eyes had a spherical equivalent within \pm 0.50 and $\pm 1.00 \mathrm{D}$, respectively. Other studies reporting the refractive outcomes of WFG LASIK using the same high resolution aberrometer (iDesign) and excimer laser (STAR S4IR) have found percentages of eyes with spherical equivalent within $\pm 0.50 \mathrm{D}$ of around $100 \% .^{2,3,16,17}$ In our series, a slight trend to overcorrection was found, with a 90-day postoperative mean spherical equivalent of $+0.18 \pm 0.31 \mathrm{D}$ and a maximum postoperative value of spherical equivalent of +1.12 D. This may be due to the trend of overcorrecting slightly, as happened with classical nomograms, but without considering the potential effect on 
refractive correction accuracy with the implementation of the new ablation profile. In any case, this minimal trend to overcorrection can be modelled by linear regression and corrected if necessary. Concerning UDVA, a total of $93.3 \%, 98.9 \%$ and $100 \%$ of eyes achieved values of $20 / 16,20 / 20$ and $20 / 25$ or better at 90 days after surgery, respectively. These findings are very consistent with those reported by previous authors using different type of WFG ablation profiles. ${ }^{2-4,15}$ In our series, the minimal trend to hyperopia did not have effect on UDVA as most of our patients were young adults and could compensate the minimal residual error with accommodation. The percentage of eyes with postoperative UDVA of 20/16 or better was higher with TI-WFG LASIK than those percentages reported by previous authors with WFG LASIK (74.14\% Shetty et al, ${ }^{15} 12 \%$ Duran et $\mathrm{al}^{2}$ ).

Concerning the correction of astigmatism, a vector analysis of changes occurring in manifest cylinder with surgery has been performed to provide a more complete evaluation of astigmatic changes, including magnitude and cylinder. Mean ME was remarkably close to zero at all postoperative visits, with no significant changes between them. This indicates that the surgical procedure evaluated was highly predictive in terms of correction of magnitude of cylinder. Likewise, the DV was in the range from 0.20 to $0.26 \mathrm{D}$ at all postoperative visits, with a minimal but statistically significant increase at the end of the follow-up. A mean value of CI of 1.01 was found at 90 days after surgery, confirming the excellent level of predictability of correction of the magnitude of astigmatism. Some authors have reported slightly lower values of CI after WFG LASIK, indicating a minimal trend to undercorrection. ${ }^{2,16,19,20}$ Schallhorn et al. ${ }^{20}$ found in a study enrolling 611 eyes with astigmatism of $2 \mathrm{D}$ or more and undergoing WFG LASIK using the CustomVue platform that there was a minimal trend to undercorrection of astigmatism, with a mean CI at 1 month postoperatively of $0.92 \pm$ 
0.14. Likewise, Durán et $\mathrm{al}^{2}$ found in another study evaluating the outcomes of WFG LASIK in myopic eyes with low to moderate levels of astigmatism that the mean CI at 90 days postoperatively was 0.86 . Besides the precision in the reduction of the magnitude of astigmatism, the laser procedure evaluated was also precise in terms of applying the astigmatic correction in the correct axis, with a mean $\mathrm{AE}$ at the end of follow-up of $0.17^{\circ}$. This mean value remarkably close to zero is lower than those mean values reported by other authors evaluating the astigmatic correction achieved with WFG LASIK using different excimer laser platforms. ${ }^{2,16,19-21}$

Besides all these changes, a significant improvement was observed in CDVA, with all eyes achieving a postoperative CDVA of 20/20 or better at the end of the follow-up and $50.0 \%$ of eyes gaining 1 line of CDVA. This confirms that the surgical procedure evaluated did not only correct the spherocylindrical error, but also it optimized the ocular optics. This percentage of gain of lines of CDVA is similar or somewhat lower than those reported by other authors in previous studies evaluating the outcomes of WFG LASIK. ${ }^{2-4,8,15}$ This is consistent with the outcomes obtained in terms of ocular aberrations and OSI. Specifically, small although statistically significant increases were observed in HOA RMS and spherical aberration Zernike term, with only $7 \%$ and $0 \%$ of eyes showing postoperative values of more than $0.50 \mu \mathrm{m}$, respectively. Likewise, the change is primary coma components was minimal, maintaining the postoperative levels of this aberration within the normal range for a healthy population. ${ }^{22}$ Therefore, TI-WFG LASIK not only generates an ablation profile able to correct the spherocylindrical error accurately but also maintains the level of ocular aberration within a physiological range. ${ }^{22}$ Different studies evaluating the outcomes of WFG LASIK have demonstrated that WFG procedures can control the induction of high order aberrations in minimally aberrated eyes as well as can reduce the level of such 
aberrations in significantly aberrated eyes. ${ }^{2,3,15-17}$ The sample evaluated in the current study only included healthy eyes with low levels of high order aberrations and therefore a minimal induction of such aberrations and maintaining a physiological aberrometric level was expected. Indeed, the mean value of OSI obtained postoperatively in the sample evaluated $(0.71 \pm 0.44)$, which is within the physiological range defined for the healthy human eye. ${ }^{23}$

According to all these outcomes, TI WFG-LASIK is safe and efficacious for the correction of myopic astigmatism, with an accurate correction of magnitude and axis of cylinder. Besides the nomogram factor and the inclusion of eyes with very low levels of high order aberrations, the slight trend to overcorrection of sphere observed in the current series as well as the relatively limited impact of the surgery on high order aberrations may be also influenced by other factors such as the creation of the flap. However, this seems to be a factor with minimal impact considering that the flap was created using the femtosecond technology that has been shown to generate planar flaps with minimal induction of aberrations. ${ }^{24}$ Hood et $\mathrm{al}^{25}$ demonstrated that femtosecond laser flap thickness in the range of $90-110 \mu \mathrm{m}$ (as in our series) was not associated with poorer visual acuity or clinically significant induction of high order aberrations after uncomplicated customized myopic LASIK.

Finally, patient satisfaction outcomes were evaluated. All patients answering the subjective questionnaire indicated that they were satisfied with the final outcomes, would have the same surgical procedure again if necessary, and would recommend the procedure to their friends and relatives. This is consistent with the good visual, refractive and optical quality outcomes obtained. Chen and Manche ${ }^{4}$ reported that $88.1 \%$ of patients undergoing WFG LASIK in a study enrolling 42 myopic patients were satisfied with their vision without correction, with visual function, perceptions, 
and problems with corrective lenses subscales of the Refractive Status and Vision Profile questionnaire improving significantly.

Several limitations should be acknowledged in this prospective study. One of them was not including a control group undergoing LASIK with an optimized ablation profile or any type of previously developed WFG ablation profile. Therefore, no consistent conclusions about the potential benefit of the technique evaluated over other types of treatments can be extracted, being the current study only focused on the evaluation of efficacy and safety of this new laser refractive surgery procedure. Likewise, the evaluation of the visual quality in terms of contrast sensitivity changes should have also been included as this evaluation is crucial for a better understanding of visual perception changes after any corneal refractive surgery procedure. Future comparative studies should be performed including an analysis of contrast sensitivity changes and analyzing the evolution of the outcomes in the long term.

In conclusion, TI-WFG LASIK is a new approach for the laser surgical correction of myopia and myopic astigmatism, with preservation of the ocular optical quality and high level of patient satisfaction associated. This type of treatments provides a very predictable correction of astigmatism, with no trend to over or undercorrection. Future studies should be conducted to evaluate the results of this refractive surgery technique in the long term in a larger sample. Likewise, comparative studies of this new approach with no topography-optimized WFG LASIK and topography-guided LASIK should be performed to define its real benefit in clinical terms over the pre-existing techniques. 


\section{REFERENCES}

1.- Ryan DS, Sia RK, Rabin J, Rivers BA, Stutzman RD, Pasternak JF, Eaddy JB, Logan LA, Bower KS. Contrast sensitivity after wavefront-guided and wavefrontoptimized PRK and LASIK for myopia and myopic astigmatism. J Refract Surg 2018; 34: 590-596.

2.- Durán JA, Gutiérrez E, Atienza R, Piñero DP. Vector analysis of astigmatic changes and optical quality outcomes after wavefront-guided laser in situ keratomileusis using a high-resolution aberrometer. J Cataract Refract Surg 2017; 43: 1515-1522.

3.- Moussa S, Dexl A, Krall EM, Dietrich M, Arlt EM, Grabner G, Ruckhofer J. Comparison of short-term refractive surgery outcomes after wavefront-guided versus non-wavefront-guided LASIK. Eur J Ophthalmol 2016; 26: 529-535.

4.- Chen SP, Manche EE. Patient-reported vision-related quality of life after bilateral wavefront-guided laser in situ keratomileusis. J Cataract Refract Surg 2019; 45: 752759.

5.- Manche E, Roe J. Recent advances in wavefront-guided LASIK. Curr Opin Ophthalmol 2018; 29: 286-291.

6.- Piñero DP, Soto-Negro R, Ruiz-Fortes P, Pérez-Cambrodí RJ, Fukumitsu H. Analysis of intrasession repeatability of ocular aberrometric measurements and validation of keratometry provided by a new integrated system in mild to moderate keratoconus. Cornea 2019; 38: 1097-1104.

7.- Piñero DP, Soto-Negro R, Ruiz-Fortes P, Pérez-Cambrodí RJ, Fukumitsu H. Interchangeability of corneal curvature and asphericity measurements provided by three different devices. Int J Ophthalmol 2019; 12: 412-416. 
8.- Roe JR, Manche EE. Prospective, randomized, contralateral eye comparison of wavefront-guided and wavefront-optimized laser in situ keratomileusis. Am J Ophthalmol 2019; 207: 175-183.

9.- Thibos LN, Horner D. Power vector analysis of the optical outcomes of refractive surgery. J Cataract Refract Surg 2001; 27: 80-85.

10.- Alpins NA. New method of targeting vectors to treat astigmatism. J Cataract Refract Surg 1997; 23: 65-75.

11.- Alpins N. Astigmatism analysis by the Alpins method. J Cataract Refract Surg $2001 ; 27: 31-49$.

12.- Stonecipher K, Parrish J, Stonecipher M. Comparing wavefront-optimized, wavefront-guided and topography-guided laser vision correction: clinical outcomes using an objective decision tree. Curr Opin Ophthalmol 2018; 29: 277-285.

13.- Moshirfar M, Somani AN, Motlagh MN, Vaidyanathan U, Sumsion JS, Barnes JR, Ronquillo YC. Comparison of FDA-reported visual and refractive outcomes of the toric ICL lens, SMILE, and topography-guided LASIK for the correction of myopia and myopic astigmatism. J Refract Surg 2019; 35: 699-706.

14.- Imamoglu S, Kaya V, Oral D, Perente I, Basarir B, Yilmaz OF. Corneal wavefrontguided customized laser in situ keratomileusis after penetrating keratoplasty. J Cataract Refract Surg 2014; 40: 785-92.

15.- Shetty R, Matalia H, Nandini C, Shetty A, Khamar P, Grover T, Sinha Roy A. wavefront-guided LASIK has comparable ocular and corneal aberrometric outcomes but better visual acuity outcomes than SMILE in myopic eyes. J Refract Surg 2018; 34: $527-532$. 
16.- Kobashi H, Kamiya K, Igarashi A, Takahashi M, Shimizu K. Two-years results of small-incision lenticule extraction and wavefront-guided laser in situ keratomileusis for myopia. Acta Ophthalmol 2018; 96: e119-e126.

17.- Khalifa MA, Ghoneim A, Shafik Shaheen M, Aly MG, Piñero DP. Comparative analysis of the clinical outcomes of SMILE and wavefront-guided LASIK in low and moderate myopia. J Refract Surg 2017; 33: 298-304.

18.- Moshirfar M, Shah TJ, Skanchy DF, Linn SH, Kang P, Durrie DS. Comparison and analysis of FDA reported visual outcomes of the three latest platforms for LASIK: wavefront guided Visx iDesign, topography guided WaveLight Allegro Contoura, and topography guided Nidek EC-5000 CATz. Clin Ophthalmol 2017; 11: 135-147.

19.- Khalifa MA, Alsahn MF, Shaheen MS, Pinero DP. Comparative analysis of the efficacy of astigmatic correction after wavefront-guided and wavefront-optimized LASIK in low and moderate myopic eyes. Int J Ophthalmol 2017; 10: 285-292.

20.- Schallhorn SC, Venter JA, Hannan SJ, Hettinger KA. Clinical outcomes of wavefront-guided laser in situ keratomileusis to treat moderate-to-high astigmatism. Clin Ophthalmol 2015; 9: 1291-8.

21.- Lee MD, Toy BC, Manche EE. Astigmatic outcomes in myopic wavefront-guided laser in situ keratomileusis versus wavefront-guided photorefractive keratectomy using vector analysis. J Cataract Refract Surg 2018; 44: 1350-1354.

22.- Piñero DP, López-Navarro A, Cabezos I, de Fez D, Caballero MT, Camps VJ. Intrasession repeatability of refractive and ocular aberrometric measurements obtained using a multidiagnostic device in healthy eyes. Clin Optom 2017; 9: 91-96.

23.- Xu CC, Xue T, Wang QM, Zhou YN, Huang JH, Yu AY. Repeatability and reproducibility of a double-pass optical quality analysis device. PLoS One 2015; 10 : e0117587. 
24.- Garcia-Gonzalez M, Bouza-Miguens C, Parafita-Fernandez A, Gros-Otero J, Cañones-Zafra R, Villa-Collar C, Teus MA. Comparison of visual outcomes and flap morphology using 2 femtosecond-laser platforms. J Cataract Refract Surg 2018; 44: 7884.

25.- Hood CT, Krueger RR, Wilson SE. The association between femtosecond laser flap parameters and ocular aberrations after uncomplicated custom myopic LASIK. Graefes Arch Clin Exp Ophthalmol 2013; 251: 2155-62. 


\section{Figure legends}

Figure 1.- Summary of the visual and refractive results using the standard graphs for reporting refractive surgery outcomes. (a) Uncorrected distance visual acuity. (b) Change in corrected distance visual acuity. (c) Spherical equivalent attempted versus

achieved. (d) Spherical equivalent refractive accuracy. (e) Refractive astigmatism. (f) Stability of spherical equivalent refraction. 


\section{TABLES}

Table 1.- Evolution from the WaveScan system to the iDesign 2.0 system from Johnson \& Johnson Vision to calculate wavefront-guided ablation profiles. Abbreviation: K1, flattest keratometric reading; K2, steepest keratometric reading; cx and cy, Cartesian coordinates of the distance between pupil center and corneal vertex; Q, conic constant of adjustment; CT, corneal topography.

\begin{tabular}{|l|c|c|}
\hline Version & \multicolumn{1}{|c|}{ Cosine Effect } & Wavefront Propagation \\
\hline WaveScan & Uses K1, K2, not K2 axis & Uses of K1, K2, K2 axis \\
& Uses population mean of 0 for Q & Uses population mean of -0.25 for Q \\
& Does not use cx, cy (CT not available) & Does not use cx, cy (CT not available) \\
\hline iDesign 1.x & Uses K1, K2, K2 axis & Uses K1, K2, K2 axis \\
& Uses population mean of -0.25 for Q & Uses population mean of -0.25 for Q \\
& Uses cx, cy from CT & Does not use cx, cy \\
\hline iDesign 2.0 & Uses full topography, point by point & Uses full topography, point by point \\
& Uses cx, cy from CT & Uses cx, cy from CT \\
\hline
\end{tabular}


Table 2.- Summary of the preoperative and postoperative visual and refractive data of the analyzed sample.

\begin{tabular}{|c|c|c|c|c|c|c|}
\hline $\begin{array}{c}\text { Mean (SD) } \\
\text { Median } \\
\text { (Range) }\end{array}$ & Preoperative & 1 day postop & 7 day postop & 30 days postop & 90 days postop & $\begin{array}{c}\text { p-value } \\
\text { (preop-90 } \\
\text { days postop) }\end{array}$ \\
\hline $\begin{array}{c}\text { LogMAR } \\
\text { UDVA }\end{array}$ & $\begin{array}{c}1.02(0.38) \\
1.00(0.10 \text { to } 1.60)\end{array}$ & $\begin{array}{c}-0.07(0.07) \\
-0.08(-0.18 \text { to } 0.22)\end{array}$ & $\begin{array}{c}-0.08(0.07) \\
-0.08(-0.18 \text { to } 0.22)\end{array}$ & $\begin{array}{c}-0.09(0.07) \\
-0.08(-0.18 \text { to } 0.10)\end{array}$ & $\begin{array}{c}-0.11(0.06) \\
-0.08(-0.18 \text { to } 0.10)\end{array}$ & 0.001 \\
\hline $\begin{array}{c}\text { LogMAR } \\
\text { CDVA }\end{array}$ & $\begin{array}{c}-0.08(0.02) \\
-0.08(-0.18 \text { to } 0.00)\end{array}$ & $\begin{array}{c}-0.09(0.05) \\
-0.08(-0.18 \text { to } 0.10)\end{array}$ & $\begin{array}{c}-0.10(0.05) \\
-0.08(-0.18 \text { to } 0.00)\end{array}$ & $\begin{array}{c}-0.11(0.05) \\
-0.08(-0.18 \text { to } 0.00)\end{array}$ & $\begin{array}{c}-0.13(0.05) \\
-0.13(-0.18 \text { to } 0.00)\end{array}$ & $<0.001$ \\
\hline Sphere (D) & $\begin{array}{c}-2.92(1.35) \\
-2.81(-6.25 \text { to } 0.00)\end{array}$ & $\begin{array}{c}0.42(0.28) \\
0.37(0.00 \text { to } 1.25)\end{array}$ & $\begin{array}{c}0.31(0.27) \\
0.25(-0.50 \text { to } 1.00)\end{array}$ & $\begin{array}{c}0.36(0.31) \\
0.25(-0.25 \text { to } 1.25)\end{array}$ & $\begin{array}{c}0.31(0.32) \\
0.25(-0.25 \text { to } 1.37)\end{array}$ & $<0.001$ \\
\hline Cylinder (D) & $\begin{array}{c}-0.62(0.49) \\
-0.50(-2.00 \text { to } 0.50)\end{array}$ & $\begin{array}{c}-0.19(0.19) \\
-0.25(-1.00 \text { to } 0.25)\end{array}$ & $\begin{array}{c}-0.23(0.21) \\
-0.25(-0.75 \text { to } 0.00)\end{array}$ & $\begin{array}{c}-0.21(0.22) \\
-0.25(-1.00 \text { to } 0.00)\end{array}$ & $\begin{array}{c}-0.26(0.23) \\
-0.25(-1.00 \text { to } 0.00)\end{array}$ & $<0.001$ \\
\hline $\begin{array}{c}\text { Spherical } \\
\text { equivalent (D) }\end{array}$ & $\begin{array}{c}-3.23(1.36) \\
-3.13(-6.75 \text { to }-0.50)\end{array}$ & $\begin{array}{c}0.33(0.28) \\
0.25(-0.25 \text { to } 1.00)\end{array}$ & $\begin{array}{c}0.20(0.27) \\
0.25(-0.75 \text { to } 0.75)\end{array}$ & $\begin{array}{c}0.26(0.29) \\
0.25(-0.38 \text { to } 1.00)\end{array}$ & $\begin{array}{c}0.18(0.31) \\
0.13(-0.50 \text { to } 1.12)\end{array}$ & $<0.001$ \\
\hline $\mathbf{J}_{0}(\mathrm{D})$ & $\begin{array}{c}0.07(0.33) \\
0.07(-0.86 \text { to } 1.00)\end{array}$ & $\begin{array}{c}0.02(0.11) \\
0.00(-0.35 \text { to } 0.50)\end{array}$ & $\begin{array}{c}0.05(0.13) \\
0.00(-0.25 \text { to } 0.37)\end{array}$ & $\begin{array}{c}0.04(0.12) \\
0.00(-0.46 \text { to } 0.35)\end{array}$ & $\begin{array}{c}0.06(0.15) \\
0.00(-0.48 \text { to } 0.50)\end{array}$ & 0.946 \\
\hline $\mathrm{J}_{45}$ (D) & $\begin{array}{c}0.02(0.21) \\
0.00(-0.62 \text { to } 0.87)\end{array}$ & $\begin{array}{c}0.00(0.06) \\
0.00(-0.16 \text { to } 0.25)\end{array}$ & $\begin{array}{c}0.00(0.08) \\
0.00(-0.16 \text { to } 0.26)\end{array}$ & $\begin{array}{c}0.00(0.08) \\
0.00(-0.20 \text { to } 0.32)\end{array}$ & $\begin{array}{c}-0.01(0.07) \\
0.00(-0.25 \text { to } 0.15)\end{array}$ & 0.234 \\
\hline
\end{tabular}


Table 3.- Ocular astigmatic changes analyzed by vector analysis. Abbreviations: TIA, targeted intended astigmatism; SIA, surgically induced astigmatism; DV, difference vector; $\mathrm{ME}$, magnitude of error; $\mathrm{AE}$, angle of error; $\mathrm{CI}$, correction index; $\mathrm{SD}$, standard deviation.

\begin{tabular}{|c|c|c|c|c|c|}
\hline $\begin{array}{c}\text { Mean (SD) } \\
\text { Median (Range) }\end{array}$ & 1 day & 7 days & 30 days & 90 days & $\begin{array}{c}\text { p-value } \\
(1-90 \\
\text { days })\end{array}$ \\
\hline TIA (D) & $\begin{array}{c}0.69(0.45) \\
0.50(0.25 \text { to } 2.00)\end{array}$ & $\begin{array}{c}0.69(0.45) \\
0.50(0.25 \text { to } 2.00)\end{array}$ & $\begin{array}{c}0.69(0.45) \\
0.50(0.25 \text { to } 2.00)\end{array}$ & $\begin{array}{c}0.69(0.45) \\
0.50(0.25 \text { to } 2.00)\end{array}$ & 0.999 \\
\hline SIA (D) & $\begin{array}{c}0.71(0.48) \\
0.51(0.03 \text { to } 2.21)\end{array}$ & $\begin{array}{c}0.67(0.45) \\
0.51(0.00 \text { to } 2.04)\end{array}$ & $\begin{array}{c}0.65(0.45) \\
0.50 \text { (0.07 to } 2.00)\end{array}$ & $\begin{array}{c}0.65(0.43) \\
0.52(0.00 \text { to } 1.99)\end{array}$ & 0.205 \\
\hline DV (D) & $\begin{array}{c}0.20(0.19) \\
0.25(0.00 \text { to } 1.00)\end{array}$ & $\begin{array}{c}0.24(0.22) \\
0.25(0.00 \text { to } 0.75)\end{array}$ & $\begin{array}{c}0.22(0.23) \\
0.25(0.00 \text { to } 1.00)\end{array}$ & $\begin{array}{c}0.26(0.24) \\
0.25(0.00 \text { to } 1.00)\end{array}$ & 0.005 \\
\hline ME (D) & $\begin{array}{c}0.02(0.22) \\
0.00(-0.82 \text { to } 0.74)\end{array}$ & $\begin{array}{c}-0.02(0.22) \\
0.00(-0.50 \text { to } 0.75)\end{array}$ & $\begin{array}{c}-0.03(0.21) \\
0.00(-0.50 \text { to } 0.76)\end{array}$ & $\begin{array}{c}-0.04(0.24) \\
0.00(-0.50 \text { to } 0.80)\end{array}$ & 0.205 \\
\hline CI & $\begin{array}{c}1.06(0.45) \\
1.00(0.07 \text { to } 2.96)\end{array}$ & $\begin{array}{c}1.03(0.42) \\
1.00(0.00 \text { to } 2.44)\end{array}$ & $\begin{array}{c}0.99(0.50) \\
1.00(0.28 \text { to } 4.05)\end{array}$ & $\begin{array}{c}1.01(0.56) \\
1.00(0.00 \text { to } 4.19)\end{array}$ & 0.835 \\
\hline$\overline{A E}\left(^{\circ}\right)$ & $\begin{array}{c}0.40(0.44) \\
0.33(0.00 \text { to } 2.00)\end{array}$ & $\begin{array}{c}0.48(0.54) \\
0.31(0.00 \text { to } 2.00)\end{array}$ & $\begin{array}{c}0.48(0.66) \\
0.33(0.00 \text { to } 4.00)\end{array}$ & $\begin{array}{c}0.17(0.18) \\
0.14(0.00 \text { to } 0.80)\end{array}$ & $<0.001$ \\
\hline
\end{tabular}


Table 4.- Preoperative and postoperative aberrometric data. Abbreviations: RMS, root mean square; HOA, higher order aberrations; SD, standard deviation.

\begin{tabular}{|c|c|c|c|c|}
\hline $\begin{array}{c}\text { Mean (SD) } \\
\text { Median (Range) }\end{array}$ & Preop & 30 days postop & 90 days postop & $\begin{array}{c}\text { p-value (preop-90 } \\
\text { days) }\end{array}$ \\
\hline HOA RMS $(\mu \mathrm{m})$ & $\begin{array}{c}0.28(0.08) \\
0.27(0.07 \text { to } 0.49)\end{array}$ & $\begin{array}{c}0.34(0.09) \\
0.33(0.18 \text { to } 0.61)\end{array}$ & $\begin{array}{c}0.34(0.11) \\
0.35(0.09 \text { to } 0.71)\end{array}$ & $<0$ \\
\hline Vertical coma $(\mu \mathrm{m})$ & $\begin{array}{c}0.05(0.15) \\
0.07(-0.30 \text { to } 0.38)\end{array}$ & $\begin{array}{c}-0.08(0.18) \\
-0.10(-0.45 \text { to } 0.47)\end{array}$ & $\begin{array}{c}-0.12(0.17) \\
-0.14(-0.47 \text { to } 0.49)\end{array}$ & $\overline{<0.001}$ \\
\hline Horizontal coma $(\mu \mathrm{m})$ & $\begin{array}{c}-0.01(0.09) \\
-0.02(-0.24 \text { to } 0.28)\end{array}$ & $\begin{array}{c}-0.06(0.12) \\
-0.06(-0.42 \text { to } 0.20)\end{array}$ & $\begin{array}{c}-0.05(0.14) \\
-0.07(-0.41 \text { to } 0.35)\end{array}$ & 0.007 \\
\hline Spherical aberration $(\mu \mathrm{m})$ & $\begin{array}{c}0.07(0.09) \\
0.07(-0.19 \text { to } 0.37)\end{array}$ & $\begin{array}{c}0.14(0.10) \\
0.13(-0.22 \text { to } 0.38)\end{array}$ & $\begin{array}{c}0.13(0.10) \\
0.13(-0.20 \text { to } 0.37)\end{array}$ & $<0.001$ \\
\hline
\end{tabular}

